\title{
Mutación y ¿quiebra? constitucional de la Unión Europea
}

\author{
Agustín José Menéndez \\ Profesor .Universidad de León \\ altierospinelli@gmail.com
}

\begin{abstract}
Resumen
La serie de crisis que sufre la Unión Europea desde finales de 2006 requieren un análisis sistemático desde una perspectiva constitucional. El presente trabajo tiene como principal objetivos el jurídico-dogmático de esclarecer el contenido sustantivo de la transformación constitucional de la Unión Europea a resultas de las medidas adoptadas para contener y eventualmente superar las citadas crisis; y el valorativo de determinar cuáles son las principales consecuencias que la mutación constitucional en marcha tiene sobre la integridad del ideal regulador del derecho constitucional de los Estados Miembros y de la Unión Europea, el Estado Social y Democrático de Derecho. En este artículo se sostiene que existen razones fundadas para concluir que la mutación constitucional pone en peligro la integridad del edificio constitucional europeo, o lo que es lo mismo, la transformación del derecho europeo en marcha conducirá a la quiebra del estado constitucional, salvo que se ponga remedio y fuerce al tren político, económico y social a cambiar de binario constitucional (a volver, en buena medida, al binario constitucional).
\end{abstract}

Palabras clave

Derecho constitucional de la Unión Europea. Relación entre ordenamientos jurídicos. Crisis constitucional. Estado de excepción. Estado Social y Democrático de Derecho. Mutación Constitucional.

\section{Constitutional Mutation and Bankruptcy? of the European Union}

Abstract:

The manifold and overlapping crises of the European Union call for a systematic analysis from the perspective of constitutional law. In this article the reader is provided with a legal-dogmatic analysis of the punctual decisions and structural reforms that have been taken to contain and overcome the economic, financial, fiscal, macroeconomic and political crises; an elucidation of the resulting constitutional transformation of European Union law; and a normative assessment of the implications that the resulting constitutional mutation has, very especially with respect to the integrity of the regulatory ideal of the Social and Democratic Rechtsstaat. The main thesis of the article is that the ongoing constitutional mutation constitutes a direct threat to democratic constitutionalism in Europe. Either the constitutional changes are halted and reversed, or democratic politics is bound to become an empty shell.

\section{Keywords:}

Constitutional law of the European Union. Conflicts between legal orders. Constitutional crisis. State of emergency. Social and Democratic Rechtsstaat. Constitutional Mutation. 
"Si queréis ir de peregrinaje al lugar donde nació vuestra constitución, debéis ir a las montañas donde cayeron los partisanos, a las cárceles donde fueron
hechos prisioneros, a los campos en los que fueron ahorcados. Alli donde murió un italiano tratando de rescatar la libertad y la dignidad, alli es donde tenéis
que ir con el pensamiento, porque alli fue donde nació nuestra constitución"

Piero Calamandrei

"La libre competencia que tome como paradigma el rastro, no garantiza ni la mejor calidad de los servicios ni siquiera su más bajo coste"

Miguel Herrero y Rodríguez de Miñón

“(...) Y al contrario, la causa de la integración europea terminaría viéndose lastrada si la integración monetaria se pusiese en marcha pero fracasase. El riesgo implícito en la union monetaria deriva de la pérdida del poder [nacional] de alterar el tipo de cambio; tal pérdida podría conducir a que los países más estables sufriesen una inflación excesiva o que, por el contrario, los países con tasas más altas de inflación viesen socavada su prosperidad; pérdida frente a la que sería dificil reaccionar porque se manifestaría no como un desajuste en la balanza de pagos sino como un problema "regional". Este peligro es especialmente intenso en el contexto europeo, porque las distintas tradiciones y estructuras institucionales nacionales pueden generar tendencias inconsistentes en términos de costes por unidad en diferentes regiones "nacionales". Si las cosas fuesen así, sería desastroso, porque tales fuerzas, una vez liberadas, llevarían a la destrucción de la unión monetaria"

Altiero Spinelli, La Aventura Europea, 1973, 80

\section{INTRODUCCIÓN}

La Unión Europea y sus Estados Miembros han sido sacudidos por varias y simultáneas crisis (económica, financiera, fiscal, de gobierno macroeconómico y política) desde finales de 2006. La fuerza de tales crisis no sólo ha provocado múltiples jirones en el tejido constitucional europeo sino que ha conducido a decisiones que de forma más o menos querida, de forma más o menos explícita, han supuesto cambios fundamentales en el derecho constitucional material (no siempre en el formal) de la Unión Europea y de sus Estados Miembros. Dicho de otro modo, las crisis europeas han dado lugar a una profunda mutación del derecho constitucional europeo. Como es habitual en estos casos, las transformaciones han sido el resultado de un cúmulo de decisiones ${ }^{1}$ tomadas siguiendo procedimientos escasamente ortodoxos, o lo que es lo mismo, al margen de los procesos "estándar" de reforma de los Tratados o de las constituciones nacionales, a través de peculiares cabildeos intergubernamentales (piénsese en el llamado Tratado de Estabilidad, o su antecedente, el llamado Pacto por el Euro Plus²), convirtiendo al procedimiento legislativo ordinario en cauce de modificaciones constitucionales (considérese el paso al voto por minoría cualificada previsto en la reforma del Pacto de Estabilidad operado por el llamado Six Pack aún antes de la firma del Tratado de Estabilidad), alterando drásticamente el procedimiento de reforma de la constitución nacional (basta recordar nuestra veraniega reforma constitucional exprés) o simplemente ignorando lo dispuesto en las normas constitucionales nacionales (en el caso griego, el artículo 103.4 de la Constitución, que convierte en inamovibles a los funcionarios públicos, ha caído en una particular desuetudo constitucional por imperativo del llamado Memorandum of Understanding). La mayor parte de estas decisiones han sido tomadas a altas horas de la mañana tras largas sesiones del Consejo Europeo, de negociaciones con la llamada troika, y muchas al confortable abrigo del horario de apertura de las bolsas asiáticas, convertidas así en peculiar reloj del tiempo constitucional europeo. Los líderes políticos europeos han afirmado reiterado de forma constante que eran las crisis, y no ellos, quienes definían la agenda (constitucional y política), determinado las alternativas (si es que había alguna) y el resultado. Los líderes políticos han mutado en meros instrumentos de un proceso de reforma constitucional que, si tales afirmaciones fueran ciertas, se habría desarrollado de acuerdo con una peculiar lógica y secuencia cuasi espontánea.

El presente trabajo tiene como principal objetivo esclarecer el contenido sustantivo de la mutación constitucional de la Unión Europea. O dicho de otro modo, el muy modesto propósito de, diarios y publicaciones oficiales en mano, determinar, a partir de los textos legales, qué ha cambiado y que está en proceso de cambio en el derecho constitucional material de la Unión Europea. A ese objetivo de reconstrucción jurídico-dogmática se une un segundo, de valoración constitucional normativa, que implica determinar cuáles son las principales consecuencias que la mutación constitucional en marcha tiene sobre la integridad del ideal regulador del derecho constitucional de los Estados Miembros y de la Unión Europea, el Estado Social y Democrático de Derecho. A juicio de quien estas líneas suscribe, existen razones fundadas para concluir que la mutación constitucional pone en peligro la integridad del edificio constitucional europeo, o lo que es lo mismo, la transformación del derecho europeo en marcha conducirá a la quiebra del estado constitucional, salvo que se ponga remedio y se fuerce al tren político, económico y social a cambiar de binario constitucional.

$1 \quad$ Y de no-decisiones. La relevancia de la decisión de no decidir, o de no-decidir por no ponerse de acuerdo sobre qué decidir, fue destacada ya hace muchos años (en el concreto contexto del gobierno y disciplina de los mercados financieros) por Susan Strange. Véase su Casino Capitalism, Oxford: Blackwell, pp. 29-56.

2 Un término, dicho sea de paso, propio de la mercadotecnia de las grandes superficies. 


\section{LOS PRINCIPALES CAMBIOS EN EL DERECHO CONSTITUCIONAL MATERIAL EUROPEO}

\section{Centralización de Competencias}

\section{A) Seis nuevos o reforzados poderes supranacionales}

Las medidas adoptadas con el objeto de "gobernar la crisis" han conducido a una muy marcada centralización de competencias, al apoderamiento del nivel supranacional, en lo que concierne a la gestión y control de la política económica:

En primer lugar, la Comisión Europea (aunque, como veremos más tarde, sería más preciso referirse al Comisario de Asuntos Económicos y Financieros) y el Consejo de la Eurozona (una institución de nueva creación) han sido asignados importantísimos poderes con los que controlar y disciplinar (a) la política macroeconómica de los Estados Miembros (los Estados tienen ahora que prevenir y corregir los desequilibrios macroeconómicos nacionales) 3 ; (b) han visto (y muy especialmente en lo que concierne al Comisario de Asuntos Económicos y Financieros) reforzados sus poderes en lo atinente a la coordinación y supervisión de la política fiscal nacional, como resultado de (aa) una definición más restrictiva y supuestamente más precisa de las "reglas fiscales" ya existentes (muy especialmente en lo que concierne al objetivo presupuestario a medio plazo) ${ }^{4}$ y la introducción de nuevas reglas fiscales (la trayectoria de reducción del déficit ${ }^{5}$ y de la deuda pública ${ }^{6}$ ); (bb) un nuevo procedimiento de control supranacional de la disciplina presupuestaria, que incluye un ajuste automático cuando se excedan los límites fijados por las reglas fiscales ${ }^{7}$ y la sustitución de la mayoría cualificada por la minoría cualificada a la hora de tomar la decisión de sancionar a los Estados que no cumplan con las reglas y objetivos; ${ }^{8}$ (cc) la centralización de la política económica queda reflejada en la creación de un nuevo procedimiento presupuestario, el Semestre Europeo, que garantiza que las orientaciones políticas articuladas en las leyes de presupuestos nacionales serán controladas por la Comisión y el Consejo de la Eurozona antes que por los parlamentos nacionales. ${ }^{9}$

Estos cambios suponen una clara ruptura con el modelo formalmente articulado en el Tratado de Maastricht, de unión monetaria y económica asimétrica, dado que resulta cuando menos dudoso que quepa afirmar que los Estados Miembros retienen el poder de decidir su política fiscal de forma autónoma.

En segundo lugar, la discrecionalidad del Banco Central Europeo en la ejecución de la política monetaria ha aumentado de forma drástica. El objetivo de "salvar el euro" (de forma inmediata, evitar la reducción del número de Estados Miembros de la Eurozona; de forma mediata, pero quizás determinante, evitar a toda costa una pérdida de valor de los activos financieros-el capital-expresado en euros) se ha convertido en un meta-objetivo que permite "derrotar" no sólo al espíritu de los Tratados, sino en algunas ocasiones al propio tenor literal de los mismos. El Banco Central ha tomado una larga serie de medidas de política monetaria "heterodoxas" (en la peculiar jerga tan eufemística del BCE, "medidas no convencionales") formalmente justificadas mediante referencia al que se dice es el principal riesgo para la integridad de la Eurozona, los "coágulos" o "atascos" en el "canal” de trans-

3 Reglamento (UE) 1176/2011 del Parlamento Europeo y del Consejo, de 16 de noviembre de 2011, relativo a la prevención y corrección de los desequilibrios macroeconómicos, DOUE L 306, de 23 de Noviembre de 2011, pp. 25-32; Reglamento (UE) $1174 / 2011$ del Parlamento Europeo y del Consejo, de 16 de noviembre de 2011, relativo a las medidas de ejecución destinadas a corregir los desequilibrios macroeconómicos excesivos en la zona del euro, DO L 306, de 23 de Noviembre de 2011, pp. 8-11.

4 Artículo 2a, segundo párrafo del texto refundido del Reglamento 1466/97. Que a su vez los Artículos 3.1(a) y (b) del Tratado de Estabilidad precisan en sentido restrictivo, al fijar como indicador de referencia el equilibrio presupuestario o un déficit del 0.5\% del PIB, que podrá llegar al 1\% del PIB en el caso de los Estados cuyo nivel de deuda sea inferior al 60\% del PIB. Para el Tratado de Estabilidad, véase Boletín Oficial del Estado 29, de 2 de Febrero de 2013, pp. l:9078-9090, disponible en https://www.boe.es/boe/dias/2013/02/02/pdfs/BOE-A-2013-1118.pdf.

5 Artículo 5.1 segundo párrafo del texto refundido del Reglamento 1466/97. El artículo 6.3 determina la "desviación" tolerada en la ejecución del presupuesto. Para el texto refundido del Reglamento 1466/97, véase http://eur-lex.europa.eu/LexUriServ/LexUriServ.do?uri=CON SLEG:1997R1466:20111213:ES:PDF.

6 Artículo 2.1 del texto refundido del Reglamento 1467/97. En el caso italiano, con una deuda en torno al 120\% del PIB, esto exige una reducción anual de la deuda equivalente al 3\% del PIB. Dado el "patrón” histórico de crecimiento de Italia en las últimas décadas y las perspectivas de futuro, esta trayectoria de corrección de la deuda pública, requeriría la venta masiva de bienes públicos a corto y medio plazo, y ni siquiera tal cosa parece que pudiese garantizar superávits suficientes para mantener este ritmo de reducción durante los necesarios veinte años para lograr alcanzar el objetivo. De ahí que no queda duda de que esta regla implica aspirar a establecer una nueva plusmarca presupuestaria en la historia comparada de las finanzas públicas. Para el texto refundido del Reglamento 1467/97, véase http://eur-lex.europa.eu/LexUriServ/ LexUriServ.do?uri=CONSLEG:1997R1467:20111213:ES:PDF.

$7 \quad$ Artículo 3.1(e) del Tratado de Estabilidad (referencia en supra nota 4).

8 Estas nuevas normas de "procedimiento" codifican la práctica seguida en los “programas" de "asistencia financiera" a varios Estados de la Eurozona (Grecia, Portugal, Irlanda, España, Chipre) y externos a la Eurozona (Hungría, Lituania, Rumanía) desde 2008, en los que la Comisión, asistida por el Banco Central Europeo y el Fondo Monetario Internacional (la troika) ha modelado (cuando no fijado completamente) la política social, económica y laboral de los estados "asistidos" a través de los Memoranda of Understanding, con sus importantísimas y muy flexibles revisiones trimestrales.

9 Es por ello que no es en modo alguno sorprendente que el procedimiento presupuestario nacional se haya visto radicalmente modificado, muy especialmente por Directiva 2011/85/UE del Consejo, de 8 de noviembre de 2011, sobre los requisitos aplicables a los marcos presupuestarios de los Estados miembros, DO L 306, de 23 de Noviembre de 2011, pp. 41-47. 
misión de la política monetaria, metáfora médicas e hidráulicas que remiten todas ellas a que la subida de tipos de interés en los estados de la periferia de la Eurozona ha provocado que las bajadas (o eventualmente subidas) de tipos de interés decididas por el BCE no afecten al tipo de interés al que se presta dinero en tales estados, dejando sin capacidad de influencia al BCE, y generando el riesgo de una divergencia permanente, que afectaría no sólo a la integración financiera, sino a la económica en general. Mediante las mencionadas medidas heterodoxas, el Banco Central Europeo se ha arrogado de facto dos nuevas funciones:

- la de prestamista de último (y en algunos casos, los de algunos bancos de la periferia de la Eurozona, y no sólo, de primer) recurso a las entidades financieras de la Eurozona, al ofrecer refinanciación a tipos fijos y cantidades ilimitadas, durante períodos cada vez más largos (recuérdense las "macro" operaciones de refinanciación del otoño de 2011 e invierno de 2012, por un valor total superior al billón-castellano-de euros) y con niveles de exigencia en lo que concierne a las garantías del préstamo cada vez menores. A resultas de ello, no parece en modo alguno exagerado afirmar que el BCE se ha convertido en actor determinante en los mercados de intermediación financiera, y en algunos períodos, en alternativa plena a los mismos; una situación que se prolonga ya seis años, y a la que no se atisba un fin inminente. Pese a que esta función es difícil de reconciliar con lo establecido en los artículos 127.1 y 119 del Tratado de Funcionamiento de la Unión Europea, que exigen que la ejecución de la política monetaria conduzca a que la asignación de capitales sea el resultado del funcionamiento de los mercados, no de decisiones "políticas" (y las del BCE, cuando toma tales decisiones, son obviamente "políticas");

- la de prestamista por vía indirecta o interpuesta de último recurso de los Estados de la Eurozona, bien mediante la compra de deuda de estados de la Eurozona en los mercados secundarios (a través del securities markets programme iniciado en Mayo de 2010, y radicalmente ampliado en Agosto de 2011 con la compra de deuda italiana y española; sustituido, en Septiembre de 2012, por las outright monetary transactions), ${ }^{10}$ bien a través de las propias operaciones de refinanciación destinadas a las entidades financieras, dado que a las mismas no sólo han concurrido de forma estadísticamente desproporcionada las entidades financieras de los estados periféricos, sino que una buena parte del capital obtenido ha sido invertido en deuda pública del propio estado (obteniendo mediante este peculiar "carry trade" un interesante margen las entidades financieras). La condición de prestamista indirecto de último recurso plantea serias dudas de constitucionalidad a la vista del artículo 123 TFUE; la interpretación de tal precepto (que prohíbe la monetización de la deuda y la concesión de préstamos a los estados por parte del Banco Central) prevalente antes de las crisis hubiese hecho inimaginable que el Banco Central adoptase estas medidas de política monetaria heterodoxa en 2005 o 2006; aunque, ha de tenerse presente, el Banco Central Europeo ha sido comedido en el desempeño de esta función, y ha limitado su intervención a lo necesario para evitar la asfixia fiscal de los estados, sin en ningún caso permitir la recuperación de ningún margen fiscal sustantivo.

En tercer lugar, al Mecanismo Europeo de Estabilidad (sucesor del Fondo Europeo de Estabilidad Financiera y del Mecanismo Europeo de Estabilidad Financiera), peculiar institución de derecho internacional creada al amparo del nuevo artículo 136 del Tratado de Funcionamiento de la Unión Europea, ${ }^{11}$ se le ha asignado el poder (y aparentemente) los medios para prestar asistencia financiera a los Estados Miembros que experimenten una crisis financiera (de liquidez), un poder que había sido intencionalmente enervado tras la entrada en vigor del Tratado de Maastricht (si bien, y de forma un tanto paradójica, la Unión Europea en su conjunto preservaba la capacidad de prestar asistencia financiera a los Estados Miembros que no fuesen parte de la Eurozona, mediante el viejo fondo de asistencia financiera para estados que sufran un desequilibrio de su balanza de pagos).

En cuarto lugar, la Junta de Riesgos Sistémicos (una institución en la que el Banco Central Europeo desempeña un papel determinante) es la institución a la que se asigna el poder de supervisión macroprudencial del sistema

10 El programa de las outright monetary transactions carece de formalización jurídica. No deja por ello de ser paradójico que el Tribunal constitucional alemán se haya pronunciado recientemente sobre su constitucionalidad (europea y alemana), siendo así que ha determinado la constitucionalidad de las palabras dichas en una rueda de prensa (Conferencia de Prensa de Draghi y Constancio del 6 de Septiembre de 2012 , http://www.ecb.europa.eu/press/pressconf/2012/html/is120906.en.html) y de un comunicado de prensa sobre las características técnicas de las operaciones monetarias de compraventa (disponible en http://www.bde.es/f/webbde/GAP/Secciones/SalaPrensa/ComunicadosBCE/NotasInformativasBCE/12/Arc/Fic/presbce2012_99.pdf). La probabilidad de que el programa de outright monetary transactions fuese llevado ante el Tribunal de Karlsruhe fue siempre grande. Quizás el Banco Central Europeo consideró que el riesgo de declaración de inconstitucionalidad era menor dejando a la norma en status de nasciturus jurídico. Intuición que, a la vista de lo dicho por el Tribunal Constitucional alemán, no parece que careciese de fundamento.

11 Decisión del Consejo Europeo, de 25 de Marzo de 2011, que modifica el artículo 136 del Tratado de Funcionamiento de la Unión Europea en relación con un mecanismo de estabilidad para los Estados miembros cuya moneda es el euro, DOUE L 91, de 6 de Abril de 2011, pp. 1-2; Tratado Constitutivo del Mecanismo Europeo de Estabilidad, BOE 239 de 4 de Octubre de 2012, pp. I:70375-70396, disponible en http://www. boe.es/boe/dias/2012/10/04/pdfs/BOE-A-2012-12378.pdf. 
financiero europeo. Poder que antes de la crisis, y al calor de la hegemonía intelectual del monetarismo y la consiguiente creencia en la capacidad de los mercados (incluidos los financieros) de auto-estabilizarse, era visto como inneceario sino trasnochado. ${ }^{2}$

En quinto lugar, existe una clara voluntad de transferir el poder de supervisión microprudencial de las entidades financieras de la Eurozona (y potencialmente, de toda la Unión Europea, sujeto en tal caso a un peculiar acuerdo contractual suscrito por cada Estado Miembro que no es parte de la Eurozona) al nuevo "brazo" supervisor del Banco Central Europeo. Prueba de que la nueva "gobernanza" económica no elimina la tendencia europea a las asimetrías la constituye el hecho de que la transferencia de ese poder no es probable que venga acompañada de la creación de un fondo común suficientemente dotado con el que hacer frente a la eventual liquidación de entidades financieras; lo que hace de la llamada unión bancaria un peculiar "quid" sin "quo", en la que los bancos ya no nacerán ni vivirán como bancos nacionales, sino europeos; pero morirán como bancos nacionales. La transferencia de competencias supervisoras al Banco Central Europeo es sucesivo a la transformación en agencias de las entidades reguladoras supranacionales de las actividades financieras.

En sexto lugar, el Tratado de Estabilidad asigna al Tribunal de Justicia de la Unión Europea el poder de controlar la constitucionalidad europea de las reformas constitucionales nacionales mediante las que se repatríe el principio de equilibrio presupuestario. ${ }^{3} \mathrm{Si}$ el Tribunal de Justicia considera que las disposiciones nacionales son insuficientes o inadecuadas, y el Estado no altera las relevantes disposiciones de su ley fundamental, los jueces de Luxemburgo pueden multar al estado.

\section{B) ¿Resistencia Nacional?}

A la marcada tendencia a la centralización de competencias puede parecer a primera vista que resisten las instituciones, o cuando menos, algunas instituciones, de algunos Estados Miembros. La asimetría económica de la crisis (que ha golpeado intensamente a los estados periféricos de la Eurozona, y en menor medida a los del núcleo duro de la misma; condiciones, periferia y núcleo duro, reflejada no sólo en la evolución del PIB, que sólo en algunos estados ha recuperado los niveles de 2008 , sino, sobre todo, en la ahora ya bien conocida prima de riesgo) ${ }^{14}$ habría tenido su equivalencia en una asimetría constitucional.

En particular, las instituciones alemanas (y quizás en menor medida, finlandesas u holandesas) habrían retenido sus poderes, al tiempo que quizá habrían visto incluso aumentar su autoridad, lo que en el caso particular del Tribunal Constitucional o el Bundesbank, se habrían convertido en los verdaderos contrapesos europeos del Consejo Europeo o del Banco Central Europeo. Pero quizá no todo lo que reluce sea verdadero poder.

El Tribunal Constitucional alemán es en larga medida rehén de su propia y compleja posición institucional (de facto par el Tribunal de Justicia en lo que concierne al control de constitucionalidad del derecho europeo, pero de jure y debido a su limitada base de legitimidad, sólo uno de los varios tribunales constitucionales), de una consolidada jurisprudencia que se sustenta en una imagen de la constitución europea desconectada de la realidad (como puso de relieve la doctrina de las líneas rojas en materia competencial articulada en el fallo sobre el Tratado de Lisboa) y en un concepto de la unión monetaria como unión de estabilidad que no resiste un análisis empíricamente serio tras las varias crisis de los últimos años, y que lejos de abandonar, ha alicatado en la sentencia sobre el Tratado de Estabilidad y la reciente sobre las outright monetary transactions (traducidas al castellano de forma a todas luces imprecisa como operaciones monetarias de compraventa, por lo que en lo sucesivo se emplea el término anglosajón, no por cursilería, sino por ser preciso), al hacer de la unión monetaria ordoliberalmente estable parte de la cláusula de intangibilidad de la Constitución Europea. La única consecuencia realmente operativa de la jurisprudencia del TC alemán es la insistencia en el apoderamiento del Parlamento alemán.

Pero ¿Qué uso puede hacer el Parlamento alemán de su poder en solitario, en tanto que parlamento alemán? Los parlamentarios alemanes conceden off the record que no sólo la velocidad, sino la complejidad de las cuestiones sobre las que se suceden las decisiones hacen imposible un control efectivo. Baste recordar el episodio, burlesco sino fuese trágico, de las garantías exigidas por el Parlamento finlandés cuando se produjo la cordada bilateral pero coordinada de ayuda a Grecia. Estas garantías, largo tiempo mantenidas en secreto, se revelaron totalmente inútiles cuando un periodista finés logró acceder a los documentos relevantes y determinar su verdadera consistencia económica. Tanta pasión para nada, por decirlo de la mano de un novelista leonés.

12 Reglamento (UE) n 1092/2010 del Parlamento Europeo y del Consejo, de 24 de noviembre de 2010, relativo a la supervisión macroprudencial del sistema financiero en la Unión Europa y por el que se crea una Junta Europea de Riesgo Sistémico, DOUE L 331 de 15 de Diciembre de 2010, pp. 1-11.

13 Artículo 8 del Tratado de Estabilidad (referencia en supra nota 4).

14 Si bien la relación entre soberanía nacional efectiva y prima de riesgo puede ser reveladora, ese indicador no ha sido consistente a lo largo de la crisis. Hasta Agosto de 2011, Italia tenía superávits modestos en el Target 2 y un diferencial muy contenido. Cabe dudar de que ello se tradujese en niveles de soberanía por parte de Italia semejantes no ya a los de Alemania, sino a los de Francia. 
El Bundesbank, quien lo duda, retiene un importante poder de veto latente sobre las decisiones del Banco Central Europeo. Poder de veto que deriva en buena medida del hecho de que las decisiones tomadas por la entidad supranacional deben ser ejecutadas operativamente por los bancos nacionales. ${ }^{15}$ Pero, de modo muy semejante a lo que es el caso con el Tribunal Constitucional Europeo, las consecuencias necesariamente letales del ejercicio efectivo de los poderes en los que se sustenta la autoridad del Bundesbank limita la efectividad de los mismos. El Bundesbank puede ejercer su autoridad dentro del límite infranqueable de no poner en riesgo la continuidad del proyecto europeo, porque en tal caso su autoridad y su poder desaparecían por encanto. $Y$ las responsabilidades contingentes acumuladas en el sistema Target 2 dejarían de ser contingentes.

\section{El fin de la igualdad entre los Estados Miembros}

\section{A) La quiebra de la igualdad entre los estados que están dentro y los que están fuera del área monetaria única}

Varias de las medidas adoptadas en nombre la contención y superación de la crisis han provocado una nítida distinción en el contenido sustantivo del derecho constitucional y ordinario aplicable a los estados, en función de su pertenencia o no a la Eurozona, con una (variable en su composición) tercera categoría, correspondiente a los estados que estando fuera de la Eurozona, quieren compartir todo o parte del derecho constitucional de la Eurozona.

El Tratado de Estabilidad es un Tratado intergubernamental que a un mismo tiempo establece la base constitucional de algunas normas ya incluidas en el derecho secundario de la Unión (fundamentalmente en el Six Pack) o emergentes en las convenciones constitucionales de la Eurozona, al tiempo que introduce nuevas normas de rango quasi-constitucional. El Tratado ha sido firmado por veintiséis de los veintiocho Estados Miembros, o lo que es lo mismo, por todos los Estados de la Unión Europea, salvo Reino Unido y República Checa. A ello se añade que los estados que lo han ratificado no siendo Estados de la Eurozona han optado por vincularse en grados variables al Tratado de Estabilidad. Dinamarca y Rumanía se han declarado vinculados por el conjunto del Tratado.

El Mecanismo Europeo de Estabilidad ha sido constituido por virtud de un Tratado internacional (al amparo, no obstante, y como ya queda dicho, del artículo 136 del Tratado de Funcionamiento de la Unión Europea), Tratado que han ratificado tan solo los Estados de la Eurozona.

De las ocho normas de derecho secundario que conforman el "Six Pack" y el "Two Pack", cuatro de ellas vinculan exclusivamente a los Estados de la Eurozona.

El Banco Central Europeo supervisará a las entidades financieras de la Eurozona, pero no a las de los estados que no formen parte de la misma; salvo que estos últimos decidan someterse voluntaria (contractualmente) al control por parte del Banco Central; ${ }^{16}$ de esta forma se refuerza la triada Eurozona, no-Eurozona y estados que no formando parte de la Eurozona, si participan en buena medida en la zona monetaria europea.

La dinámica de la gestión permanente de una sucesión de crisis ha desencadenado procesos de duplicación, bifurcación y cooptación institucional en y por la Eurozona. ${ }^{17} \mathrm{O}$ lo que es lo mismo, cabe discernir tendencias a (a)

15 Artículo 12 del Estatuto del Banco Central Europeo.

16 Reglamento (UE) 1024/2013 del Consejo, de 15 de octubre de 2013, que encomienda al Banco Central Europeo tareas específicas respecto de políticas relacionadas con la supervisión prudencial de las entidades de crédito, DOUE L 287, de 29 de Octubre de 2013, pp. 63-89; Reglamento (UE) 1022/2013 del Parlamento Europeo y del Consejo, de 22 de octubre de 2013, que modifica el Reglamento (UE) no 1093/2010, por el que se crea una Autoridad Europea de Supervisión (Autoridad Bancaria Europea), en lo que se refiere a la atribución de funciones específicas al Banco Central Europeo en virtud del Reglamento (UE) no 1024/2013, DOUE L 287, de 29 de Octubre de 2013, pp. 5-14

17 La estabilidad de la unión monetaria asimétrica decidida en Maastricht dependía de un conjunto heteróclito y sin precedentes de normas y estructuras institucionales: (a) la asignación de competencia exclusiva en lo que a la política monetaria concierne al Banco Central Europeo, institución federal e independiente (y la consiguiente transformación de los bancos centrales nacionales a la imagen y semejanza del $\mathrm{BCE}$ ); (b) el mantenimiento formal de la competencia en materia fiscal por parte de los Estados Miembros, y por ende, de sus parlamentos; pero en este último caso sujetos a (c) un conjunto de principios constitucionales que imponían el carácter "riguroso" del manejo de la política fiscal nacional (límite de déficit, límite de deuda, prohibición de monetización de la deuda, prohibición de préstamo al estado del banco central, prohibición de préstamos obligatorios de las entidades financieras, prohibición de la mutualización de deudas); (d) el pacto de Estabilidad y Crecimiento, que articulaba el "peer review” e incluía sanciones esencialmente simbólicas (cuya efectividad sería plena sólo si no era necesario aplicarlas, momento en el cual se descubriría que eran de imposible aplicación); (e) la disciplina impuesta por los mercados financieros, ya convertidos en guardianes de la ortodoxia fiscal gracias a la conversión de la libre circulación de capitales en libertad económica plena en 1988 (Directiva 88/361) y reforzados en tal condición al extenderse la libre circulación a terceros países (y de forma unilateral), por obra y gracias del Tratado de Maastricht. Ello implicaba que, en buena medida, la estabilidad de la unión monetaria asimétrica estaba anclada en la misma concepción de la relación entre estado y mercado que subyacía al giro del mercado común al mercado único: la capacidad de auto-regulación y auto-estabilización de todos los mercados (y también, y quizás fundamentalmente, los mercados financieros). En tales circunstancias, el hecho de que Unión Europea y Eurozona no fuesen idénticas, que hubiese estados de la Unión Europea que no fuesen parte de la unión económica y monetaria, era un tanto irrelevante. La Eurozona no estaba destinada a tener un espesor político e institucional propio e independiente, sino a ser una estructura al mismo tiempo capaz de encajar de forma abierta en la economía europea, y en buena medida global, gracias a la alquimia del soft law y de la disciplina de los mercados; alquimia y disciplina que obrarían el milagro, en las condiciones propias de la "nueva economía" de transformar a la Eurozona en una zona monetaria óptima, pese a distar de serlo al inicio del proceso de integración. Las pecu- 
la aparición de estructuras institucionales propias de la Eurozona, tendencia que deriva de la presión estructural a favor de asegurar la coherencia entre el círculo de los países afectados y aquellos con derecho a voz y voto. Así, el Consejo Europeo tiene ahora su réplica en el Consejo de la Eurozona, del mismo modo que al ECOFIN corresponde, ya de forma muy consolidada, el Eurogrupo (que a resultas de la crisis se ha dotado de un Presidente permanente, del que el ECOFIN carece). A ello se une la emergente presión para desdoblar el Parlamento Europeo, lo que, como se ha observado con neta precisión, es imprescindible si se quiere que el Parlamento Europeo asuma poderes decisivos en la gestión de la política económica; (b) la cooptación de estructuras institucionales de la Unión Europea por parte de la Eurozona; y ello no sólo en el sentido de hacer un uso extensivo de las instituciones comunes (piénsese en los recursos que la supervisión de los programas de asistencia financiera requiere de la Comisión Europea), sino en la influencia determinante de los Estados de la Eurozona sobre el gobierno de la Unión en general. ¿Cabe concebir, por ejemplo, que el Presidente de la Comisión o del Consejo Europeo sean nacionales de un Estado que no forme parte de la Eurozona?

\section{B) La quiebra de la igualdad entre países acreedores y países deudores}

La segunda, y más grave quiebra, del principio de igualdad entre estados corresponde a la relación entre estados acreedores y estados deudores.

Los usos constitucionales desarrollados en la práctica de la asistencia financiera a los Estados de la Eurozona, que tienen un antecedente inmediato en la asistencia financiera a Hungría, Lituania y Rumanía a finales de 2008 y principios de 2009, y uno mediato en los programas de asistencia financiera del IMF, tal y como han sido aplicados en los años ochenta, noventa y primeros años del siglo XXI, condujeron al condicionamiento de la provisión de liquidez financiera no sólo a que la misma se dedicara en gran, cuando no completa medida, a la inyección de capital en las entidades financieras nacionales, sino también al sujeción a fuertes condiciones a la ejecución de la política fiscal, de gasto público, laboral y social. Como Scharpf y Joerges han afirmado, ${ }^{18}$ la Comisión, el Banco Central Europeo y el Fondo Monetario Internacional no sólo han impuesto procesos de devaluación interna, sino que han intervenido de forma constante y directa en el diseño del proceso de ejecución de tal devolución. Ello implica no sólo la completa y constante marginación del derecho en el proceso de gobierno (como pone de relieve la constante reescritura del Memorandum of Understanding), sino también el micro-manejo (micro-management) de la política económica en su conjunto. De esta forma se establece una neta distinción entre países que mantienen un margen soberano en el diseño y ejecución de la política fiscal, y aquellos que tienen su soberanía fiscal en suspenso.

Los usos constitucionales que conducen a la desigualdad constitucional entre estados han sido codificados jurídicamente en la nueva "gobernanza económica europea". Un paso fundamental lo constituye la generalización, por virtud del Tratado de Estabilidad, de la toma de decisiones en el proceso de control y disciplina de la política fiscal nacional, y del control y disciplina de los desequilibrios macroeconómicos nacionales, del voto por minoría cualificada (que de forma totalmente eufemística, sino neolinguista en sentido orwelliano, se denomina ahora voto por mayoría cualificada inversa). Si en términos abstractos la principal objeción a una decisión basada en una propuesta de la Comisión y el voto favorable de una minoría de los estados es el carácter ineludiblemente político (y por tanto discrecional) de la decisión de sancionar a un Estado Miembro (lo que exige como mínimo una mayoría, no una minoría, cualificada favorable), en términos concretos ha de añadirse la observación de que los estados acreedores forman una minoría cualificada en el seno del Consejo de la Eurozona y del Eurogrupo. Y que la condición de acreedor/deudor, lejos de ser variable con el tiempo, se ha demostrado tercamente estable

liares condiciones existentes en 1997 cuando se establece la paridad fija e irreversible de las monedas, unidas a los desequilibrios estructurales en el interior de la futura Eurozona, condujeron a una dinámica de divergencia estructural, que se hizo repentinamente visible en 2009 , y que permaneció oculta por la simbiosis perversa entre un núcleo duro de la eurozona exportador neto de capitales y una periferia importadora neta de los citados capitales. Bajo las nuevas condiciones de unidad monetaria, ausencia de riesgo de cambios, y una política monetaria única que creaba presiones deflacionistas en el núcleo de la eurozona e inflacionistas en la periferia, el "reciclado" de capitales excedentes del núcleo fomentó un crecimiento insostenible en la periferia. Esta dinámica no sólo fue determinante en el tamaño y dimensión de las crisis desatadas en 2007 , sino que constituye un "experimento natural” que prueba el carácter fallido del anclaje de la unión monetaria en el mercado único, y demuestra la imposibilidad manifiesta de gobernar una unión monetaria mediante el soft law y la disciplina de los mercados. De ahí la trascendencia del soft law (aunque queda dudar si el giro es hacia el derecho o hacia un soft law con coerción dura) y de ahí la creación de mecanismos institucionales y procedimientos de decisión que desempeñen el papel disciplinario que no han cumplido, ni pueden cumplir, los mercados financieros. La consecuencia inmediata de anclar la unión monetaria a una estructura institucional y a un procedimiento de decisiones es que la condición de estado de la Eurozona o de estado que no pertenece a la Eurozona deja de ser irrelevante. El principio de igualdad de Estados Miembros ha quebrado ante la dinámica de consolidación institucional y sustantiva de la Eurozona, dinámica que hace necesario establecer estructuras institucionales, procedimientos de toma de decisión y normas diferentes para los Estados de la Eurozona y aquellos que no lo son; y que conduce ineludiblemente, dado el equilibrio de números y fuerzas, a una transformación de la Unión Europea en la que los estados de la Eurozona tengan mayor capacidad de influencia sobre el conjunto de la Unión Europea que aquellos que no participan en la unión económica y monetaria.

18 Fritz Scharpf, Monetary Union, Fiscal Crisis and the Preemption of Democracy, MPIfG Discussion Paper 11/11, disponible en http://www. mpifg.de/pu/mpifg dp/dp11-11.pdf; Christian Joerges, Europe's Economic Constitution in Crisis and the emergence of a new constitutional constellation, paper delivered at the Citizenship now workshop, Uppsala, 21-22 March 2013, manuscrito en posesión del autor. 
en las últimas cuatro décadas de integración europea, como la lectura del Preámbulo a la Directiva 88/361, de libre circulación de capitales, ilustra, en particular al señalarse los estados que contarán con un régimen transitorio en atención a sus problemas asociados con la condición de estados con un desequilibrio exterior (los famosos estados GIPSI, pudenda forma de componer el acrónimo de los PIGS o PIIGS). A ello se añade que en el Tratado del Mecanismo Europeo de Estabilidad la mayoría necesaria para tomar decisiones en situaciones de urgencia (y las de prestar asistencia financiera siempre son de urgencia por definición) es del $85 \%$ de los votos. Votos que no se asignan a los Estados Miembros en atención a criterios constitucionalmente impecables, sino de acuerdo con la constitucionalmente dudosa referencia al capital suscrito por cada Estado Miembro. Clave que nuevamente favorece a los Estados acreedores. Sólo Alemania, Francia e Italia adquieren un derecho de veto que pueden ejercer aisladamente. De facto, sin embargo, sólo Alemania es libérrima en el ejercicio de tal derecho, dado que no corre el riesgo de tomar una decisión que siente un precedente que pueda llegar a serle aplicable.

\section{La voladura (incontrolada) del principio de equilibrio institucional}

La centralización de poderes económicos y sociales, y la quiebra de la igualdad entre estados se ve acompañada de la voluntadura (incontrolada) del principio de equilibrio institucional, determinante del buen funcionamiento de la correa de transmisión de legitimación democrática de los procesos políticos nacionales al europeo. El complejo proceso de forja de las voluntades generales europeas, en particular, el método comunitario tradicional y el método comunitario parlamentarizado (co-decisión) permitían asegurar un módico de intermediación estatal, y transferir legitimación democrática del nivel nacional al supranacional. Los cambios operados en el derecho constitucional material de la Unión Europea a resultas de la crisis han minado los fundamentos del principio de equilibrio institucional, dado que el poder que ha acrecido al nivel supranacional ha ido a reforzar la posición de las instituciones supranacionales que tienen una cadena de legitimación democrática más larga, bloqueando cuando no cegando el proceso de transmisión de legitimación democrática.

En primer lugar, el Banco Central Europeo (a) es el actor determinante en la ejecución de la supervisión macroprudencial del Sistema Financiero, gracias a su posición dominante en la Junta de Riesgos Sistémicos; (b) ha sido convertido en el supervisor prudencial de las instituciones financieras europeas, si bien no ha sido dotado de recursos económicos con los que hacer frente a los procesos de liquidación de las citadas entidades; (c) se le ha asignado un papel determinante en el control y disciplina de la política económica de los países sujetos a programas de asistencia financiera (dicho de forma breve, es una de las tres instituciones de la troika); (d) se ha convertido, de acuerdo con los usos constitucionales emergentes, en prestamista de último (sino primer) recurso de las instituciones financieras de la Eurozona, y prestamista (indirecto) de último recurso de los estados de la Eurozona (al menos en la medida necesaria para evitar la asfixia fiscal)

En segundo lugar, el Consejo de la Eurozona ha adquirido un poder notable. No sólo el Consejo de la Eurozona tiene la llave que abre la alacena del Mecanismo Europeo de Estabilidad, sino que del Consejo (junto a la Comisión) depende la supervisión y disciplina de la política fiscal y macroeconómica de los estados miembros. De forma paralela, y como ya quedo indicado al considerar la ruptura de la igualdad entre Estados fuera y dentro de la Eurozona, el Consejo de la Eurozona ejerce una influencia decisiva sobre el Consejo Europeo tout court, influencia que ha conducido a una capidisminución del papel de la Comisión en tanto que institución que detentaba en régimen de monopolio el derecho de iniciativa legislativa (como se deriva de la comparación de los papeles desempeñados por el Presidente del Consejo Europeo y el Presidente de la Comisión Europea en la forja de las varias reformas (Six Pack, Two Pack, Tratado de Estabilidad) de la gobernanza económica europea.

En tercer lugar, la Comisión Europea, al tiempo que ha visto, como acaba de indicarse, limitados sus poderes "tradicionales", ha salido reforzada en tanto que supervisora de la política fiscal y macroeconómica de los Estados Miembros, tanto en el marco del Semestre Europeo, como en el marco de los programas de asistencia financiera. En particular, la generalización de la minoría cualificada en materia de disciplina y sanción presupuestaria refuerza la posición de la Comisión, que operará ahora bajo la influencia (positiva para su poder) de la sombra de la minoría cualificada. Como se anticipó, no obstante, este doble movimiento de debilitamiento y de reforzamiento de la Comisión, quizá conduzca a producir tensiones en el seno de la propia institución. Quizá habría de concluirse que el "ganador neto" del proceso de transformación no es la Comisión en tanto que tal, sino el Comisario de Asuntos Económicos y Financieros.

En cuarto lugar, el Tribunal de Justicia de la Unión Europea ha adquirido nuevos poderes, en tanto que guardián de la constitucionalidad europea incluso frente a los poderes constituyentes nacionales, en lo que concierne al principio de equilibrio presupuestario. Un poder que, no obstante, sólo persiste a condición de que el Tribunal no haga nunca uso del mismo. ${ }^{19}$

19 ¿Cuántas sentencias declarando la inconstitucionalidad de una reforma constitucional nacional aprobada mediante referéndum 
En quinto lugar, el Fondo Monetario internacional se ha convertido en una institución de la Unión Europea, de conformidad con la práctica constitucional iniciada en Mayo de 2010 con la cordada bilateral y coordinada de ayuda financiera a Grecia, práctica codificada en el Six Pack.

El apoderamiento de las instituciones más débilmente representativas contrasta con el estancamiento de los poderes propios del Parlamento Europeo y de los parlamentos nacionales. No obstante la importancia que el Parlamento Europeo ha asignado a las enmiendas (más ornamentales que sustantivas) que los europarlamentarios lograron se introdujesen en las normas de derecho secundario que forman el Six Pack y el Two Pack, la Eurocámara no tiene capacidad de influencia alguna la ejecución de la "gobernanza económica europea". El Parlamento parece haberse contentado con la función esencialmente simbólica de sede del "diálogo económico europeo". Ese diálogo quizá sea el embrión de una futura parlamentarización de la política económica europea. Pero el hecho es que el poder de decisión ya se concentra en las instituciones supranacionales, y que el Parlamento Europeo, cautivo y desarmado, no puede inyectar legitimidad democrática alguna a procesos de toma de decisiones de los que es meramente espectador y discutidor.

\section{II. ¿MUTACIÓN O QUIEBRA CONSTITUCIONALES?}

De la reconstrucción jurídico-dogmática avanzada en la primera sección de este trabajo cabe concluir que las crisis y su gobierno han impulsado la transformación del derecho constitucional material de la Unión Europea, una transformación reflejada en el derecho constitucional formal (en los Tratados) de forma muy limitada. Tiene pleno sentido pues hablar de la mutación constitucional de la Unión Europea.

Resta sin embargo determinar la valoración normativa que tal mutación merezca. Desde la perspectiva propia del Estado Social y Democrático de Derecho que los Estados de la Unión Europea afirman ser, tal y como lo dispone por ejemplo el Artículo 1 de la Constitución Española de 1978, ¿Cómo ha de enjuiciarse esta transformación?

En primer lugar, la transformación ahonda la crisis (ya latente) del Estado de Derecho europeo.

Parte de la responsabilidad hay que buscarla en la hybris constitucional reflejada en el Acta Única y en el Tratado de Maastricht. Así, la prohibición de la mutualización de deudas en una unión monetaria asimétrica no sólo es una prescripción conducente a la miseria económica y política, sino un claro ejemplo de una norma de imposible cumplimiento, normas que, como indicase Lon Fuller, no merecen, por razones conceptuales, y no normativas, el nombre de derecho.

Poco parece haberse aprendido, no obstante, del fiasco de la prohibición de la mutualización de deudas, visto que se ha constitucionalizado el principio de estabilidad presupuestaria, al tiempo que se ha obligado a que el mismo sea también objeto de constitucionalización a nivel nacional (al tiempo que el Tribunal Constitucional alemán, como ya queda dicho, ha incorporado el principio al ámbito de intangibilidad constitucional). Amén de que dista de ser claro que utilidad hubiese tenido el principio a la hora de prevenir la acumulación de los déficits estructurales español e irlandés (por no hablar del aún latente alemán en relación con los capitales prestados por sus entidades financieras), es más que probable que los europeos descubran pronto que la constitucionalización de la estabilidad presupuestaria sólo conduce a devaluar el respeto del derecho constitucional.

A la hybris constitucional se une la peculiar juridificación del derecho presupuestario supranacional, muy en particular mediante la referida proliferación de reglas fiscales, que, se nos dice, reducen la discrecionalidad nacional, madre de todos los incumplimientos posteriores. Sin embargo, la supuesta trascendencia del soft law a favor de reglas jurídicas precisas es más aparente que real. Y ello porque no sólo se multiplican las nuevas reglas fiscales, sino que todas ellas se construyen a partir de un concepto no sólo indeterminado, sino en buena medida indeterminable, el de déficit estructural. El déficit estructural no es el déficit registrado (concepto que en sí mismo dista de ser objetivo, aunque sólo sea por el carácter plenamente "constructivo" del concepto mismo de PIB al que se "ancla", del que se calcula como porcentaje), ${ }^{20}$ sino el que resulta de eliminar la "interferencia" que sobre esa cifra tiene la posición en la que la economía nacional se encuentra dentro del ciclo económico. Dado que hay múltiples posibles modelos del ciclo económico, la cifra del déficit estructural depende en último extremo del modelo de ciclo económico por la que optemos ¿Por cuál habremos de hacerlo? La cuestión es compleja. En 2007 el FMI estimaba que Irlanda estaba en superávit estructural. Las cifras corregidas ahora apuntan a un profundo déficit estructural. Y es que a la complejidad a se stante del cálculo del déficit estructural se une la que deriva de la interdependencia de las economías europeas. No sólo hay que optar entre diversos modelos de ciclo económico nacional, sino relacionar todos los modelos nacionales. Ello implica que un indicador como el de déficit estructural, que tiene pleno sentido como instrumento con el que realizar proyecciones y planificar medidas macroeconómi-

podría permitirse el Tribunal de Justicia antes de provocar la explosión constitucional de la Unión Europea?

20 Diane Coyle, GDP: A Short but Affectionate History, Princeton: Princeton University Press, 2014. 
cas, es absolutamente inadecuado como pieza de un sistema sancionatorio jurídico. Tratar de usarlo de tal modo conduce a disfrazar bajo el manto de la forma jurídica una decisión en sentido schmittiano: radicalmente discrecional. Lo que no puede sino romper las costuras del Estado de Derecho.

Finalmente, los jefes de gobierno europeos han articulado algunas de las medidas de las que se hace elenco en la primera sección en espacios constitucionales que se pretendían fuera del ámbito de aplicación del derecho constitucional nacional y del derecho constitucional europeo. Así, la cordada bilateral pero coordinada a Grecia de primeros de Mayo de 2010 se articuló en el ámbito del derecho internacional, con la nada velada intención de encontrar en el mismo un espacio constitucional en el que no fuesen de aplicación los principios constitucionales fundacionales de la unión monetaria de Maastricht, y muy especialmente, la prohibición de la mutualización de la deuda pública. De igual modo, el Mecanismo Europeo de Estabilidad Financiera nació como sociedad de derecho privado luxemburguesa, sociedad que luego firmó un Acuerdo Marco con todos y cada uno de los estados Miembros, acuerdo en el que se sujeta el funcionamiento del Mecanismo al derecho inglés. ${ }^{21}$ La huida hacia el espacio constitucional vacío del derecho internacional se confirma con el Tratado de Estabilidad, pese a la adición, por insistencia del Parlamento Europeo, de los artículos que manifiestan la pía intención de incorporar el Tratado al derecho primario de la Unión en un plazo de cinco años.

Pero, en segundo lugar, hay razones de peso para concluir que el gobierno de la crisis ha dado lugar a un proceso de transformación del derecho comunitario que no sólo ha detenido el proceso de democratización del poder público europeo, sino que ha revertido el proceso.

Como ya vimos, el poder no sólo se ha centralizado en el nivel supranacional, sino que ha reforzado a las instituciones con una más indirecta y más débil legitimación democrática. A la vista de los nuevos poderes adquiridos por el Consejo de la Eurozona y el Comisario de Asuntos Económicos y Financieros, y de los usos constitucionales que aumentan la discrecionalidad del Banco Central Europeo en el manejo de la política monetaria, muchos ciudadanos llegarán a la conclusión de que no sólo poco margen de maniobra le queda a sus autoridades nacionales, sino que tampoco disponen, en tanto que ciudadanos, de medios para influir sobre las decisiones de los nuevos detentadores de los poderes públicos supranacionales, el Consejo de la Eurozona, el Comisario de Asuntos Económicos y Financieros, y el Banco Central Europeo. El trabajo sociológico de campo ha dado cuenta de una creciente sensación de humillación en la periferia de la Eurozona, que se articuló primero en un sentimiento anti-alemán (cuando no personalizado en el rechazo de Merkel) pero que ya se traduce en el colapso del consenso público a favor de la pertenencia a la Unión Europea. Quizá la traducción constitucional de ese sentimiento sea la creciente sensación de muchos ciudadanos de haberse convertido en una peculiar especie de apátridas, ciudadanos a un tiempo de estados fallidos, o crecientemente incapaces de actuar de forma determinante (estados cobardes, en la feliz expresión de Richard Murphy), y ciudadanos de una Unión Europea que aún dista de ser un vehículo de articulación de la voluntad general europea.

El déficit democrático estructural de la Europa que resulta de la transformación constitucional en marcha va bastante más allá de los raquíticos poderes del Parlamento Europeo y de los parlamentos nacionales en lo que concierne al manejo de la política económica. La ecuación de la legitimidad democrática europea no puede resolverse multiplicando los puntos de veto sin poner en riesgo la capacidad efectiva de gobernar la Unión. De ahí que la "resistencia" de las instituciones nacionales del corazón de la Eurozona sea mucho menos efectiva de lo que parece a primera vista, como indiqué en la Sección I. Al mismo tiempo, cualquier simplificación del proceso de toma de decisiones que confíe en la capacidad de legitimación de la imputación de la decisión a la voluntad general europea está destinado, aún más tras la erosión de la confianza mutua resultante de cómo se han gobernado las crisis, a provocar una crisis política de envergadura. El Banco Central Europeo puede hacer de prestamista indirecto de último recurso a los Estados de la Eurozona. ¿Pero qué quedaría del poder y autoridad del Banco Central Europeo si de esa política se derivarán pérdidas (reales o contables), por ejemplo a causa de la reestructuración de la deuda pública de un estado miembro de la Eurozona? Sancionar a un Estado Miembro de la Eurozona cuyo déficit supere el objetivo presupuestario nacional requiere ahora que la Comisión proponga y una minoría cualificada de estados disponga. En términos probabilísticos, es más fácil sancionar. Pero ¿Qué pensarían los ciudadanos del Estado sancionado si la sanción fuese decidida por una minoría de estados acreedores, estados que probablemente verían reducirse los tipos de interés que habrían de satisfacer por emitir deuda en la medida en la que los detentadores de capital del estado sancionado optarían por transferir su capital a los países sancionantes?

En tercer lugar, la capacidad de los Estados de la Unión para comportarse como Estados Sociales y Democráticos de Derecho, como factores de transformación social, capaces de remover los "obstáculos de orden econó-

21 Opción acorde con el híbrido entre agencia transnacional y hedge fund que el Mecanismo era, pero escasamente coherente con el discurso público de una buena parte de los líderes europeos, ni en lo que atañe a la "perfidia" de los mercados financieros, City incluida, ni al insuficiente compromiso del Reino Unido con la causa europea. 
mico y social que, limitando de hecho la libertad e igualdad de los ciudadanos, impidan el pleno desarrollo de la personalidad humana y la efectiva participación de todos los trabajadores en la organización política, económica y social del país" por decirlo en los términos del Artículo 3.2 de la Constitución Italiana, del que en buena medida tomaron los constituyentes españoles el tenor literal del Artículo 9.2 de la nuestra.

Los estados atrapados en el círculo vicioso de una recesión (especialmente si es asimétrica y sólo afecta a uno o un grupo reducido de estados) que deprima su actividad económica y presione déficit y deuda al alza sólo cuentan con dos palancas macroeconómicas mediante las que reequilibrar su economía: la política laboral y la política tributaria. O dicho de otra forma, el marco constitucional de la política fiscal, de forma especialmente neta y clara tras la transformación constitucional en marcha, no deja otra opción que la de practicar una devaluación interna que reduzca la acción estatal de reequilibrio entre empresarios y trabajadores (de modo que aquellos puedan valerse de su poder económico para reducir salarios y/o aumentar la productividad mediante la reducción del empleo) y que desplace la carga tributaria de forma intencionalmente regresiva, aumentado la capacidad de acumulación de capital de los empresarios, y especialmente aquellos con mayor potencial exportador, con la esperanza de que ambas medidas conduzcan a un aumento de los beneficios empresariales, de los que derive, a medio plazo, un mayor nivel de inversión, que, a largo plazo, lleve a la reactivación económica. Ello implica que la devaluación interna es, en términos constitucionales, la antítesis de la misión del Estado Social y Democrático de Derecho. La devaluación interna implica recrear los obstáculos que se interponen en el camino a la igualdad material y valerse del estado para redistribuir la riqueza socialmente producida hacia los empresarios, que suelen ser quienes tienen, antes de esa redistribución, una mejor posición económica. A ello se une la enorme carga fiscal derivada de la doble decisión de nacionalizar buena parte de las pérdidas de un sector financiero que se había convertido en intermediador de capital ficticio, y de imponer el pago de tal nacionalización a los contribuyentes de los estados periféricos, eliminando cualquier discusión acerca de los criterios normativos y prudenciales de acuerdo con los cuales habían de dividirse los costes generados por un ciclo de endeudamiento, pero también de préstamo, irresponsable, mediante el que las entidades financieras del núcleo duro de la eurozona y los deudores de la periferia crearon, de facto, una comunidad de riesgos económicos. 